\title{
Chapter 2 \\ Single Virion Tracking Microscopy \\ for the Study of Virus Entry Processes \\ in Live Cells and Biomimetic Platforms
}

\author{
Lakshmi Nathan and Susan Daniel
}

\begin{abstract}
The most widely-used assays for studying viral entry, including infectivity, cofloatation, and cell-cell fusion assays, yield functional information but provide low resolution of individual entry steps. Structural characterization provides highresolution conformational information, but on its own is unable to address the functional significance of these conformations. Single virion tracking microscopy techniques provide more detail on the intermediate entry steps than infection assays and more functional information than structural methods, bridging the gap between these methods. In addition, single virion approaches also provide dynamic information about the kinetics of entry processes. This chapter reviews single virion tracking techniques and describes how they can be applied to study specific virus entry steps. These techniques provide information complementary to traditional ensemble approaches. Single virion techniques may either probe virion behavior in live cells or in biomimetic platforms. Synthesizing information from ensemble, structural, and single virion techniques ultimately yields a more complete understanding of the viral entry process than can be achieved by any single method alone.
\end{abstract}

Keywords Fluorescence microscopy · Virion tracking · Lipid bilayer · Virus entry · Single virus particle $\cdot$ Enveloped virus $\cdot$ Non-enveloped virus $\cdot$ Infection $\cdot$ Membrane fusion · Imaging $\cdot$ Live cells $\cdot$ Biomimetics $\cdot$ Tracking

\subsection{Overview of Virus Entry}

Viruses can be broadly classified as non-enveloped or enveloped. Non-enveloped viruses are encapsulated by a protein coat, called a capsid, while enveloped viruses are encapsulated in a host-derived lipid membrane implanted with viral proteins

\footnotetext{
L. Nathan $(\bowtie) \cdot$ S. Daniel $(\bowtie)$

Robert Frederick Smith School of Chemical and Biomolecular Engineering, Cornell University, Ithaca, NY, USA

e-mail:1n258@cornell.edu; sd386@cornell.edu
} 


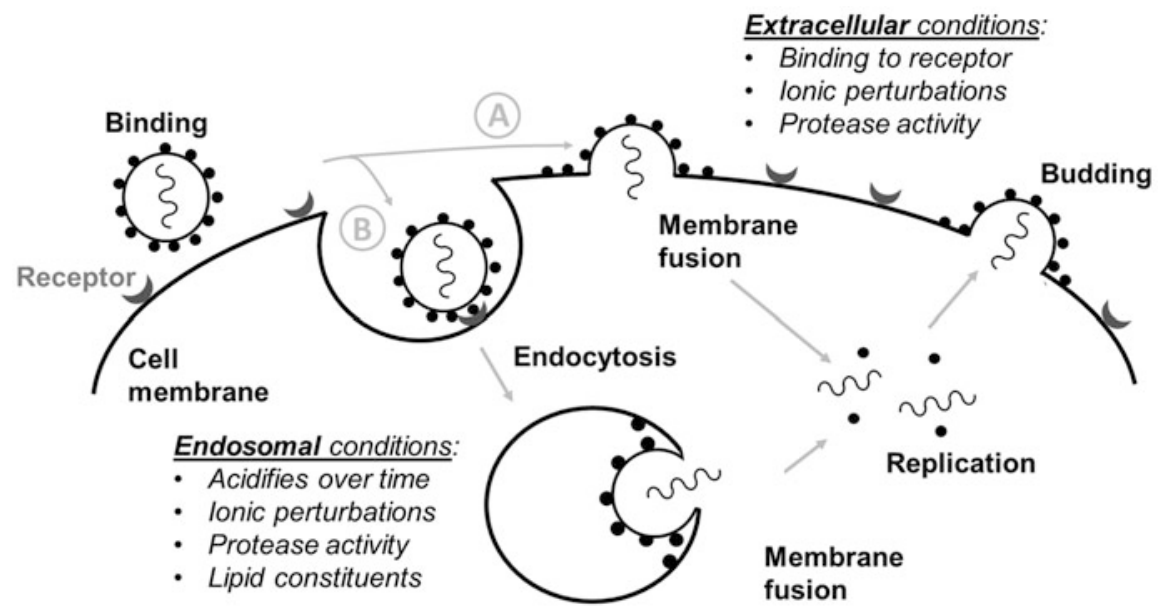

Fig. 2.1 Overview of the life cycle of an enveloped virus. The entry process begins with the virus binding to a receptor on the surface of the cell. This binding may result in (a) release of the viral genome via fusion at the plasma membrane or (b) uptake by endocytosis or macropinocytosis (not shown) followed by fusion within the endosome. The location and mechanism of fusion can be impacted by environmental conditions, including $\mathrm{pH}$, ions, protease activity, and lipid composition. Once the genome has been released into the cytosol, it can access cellular machinery, leading to replication of the viral genome and synthesis of new viral proteins. Newly synthesized virions can then exit the cell by budding

called spikes. The coat protein of non-enveloped viruses and spike proteins of enveloped viruses facilitate the virus's entry into the cell. These viral proteins engage receptors on host cells to promote attachment to the host cell surface, but after that initial binding event, non-enveloped and enveloped viruses breach host cell membranes through different pathways [1]. Non-enveloped viruses typically enter cells by endocytosis and then either lyse the intracellular compartment, or release genetic material through a pore created in the membrane of the intracellular compartment $[2,3]$. Enveloped viruses, on the other hand, must undergo membrane fusion with a cellular membrane to release their genetic material into the host cell (Fig. 2.1).

Some enveloped viruses, like coronaviruses or human immunodeficiency virus (HIV), can undergo fusion at the plasma membrane (A), while others, like influenza, fuse within endosomes (B) [4].

Binding and uncoating of nonenveloped viruses is mediated by the capsid surface or capsid proteins projecting from it. For enveloped viruses, the fusion or spike proteins embedded in the envelope are responsible for both receptor binding and membrane fusion. Membrane fusion proteins can be subdivided into three categories based on their structure [5]. Class I fusion proteins are primarily $\alpha$-helical, Class II fusion proteins contain mainly $\beta$-sheets and $\beta$-strands, and Class III fusion proteins contain a mix of both $\alpha$-helices and $\beta$-sheets. Class I and II fusion proteins require a proteolytic priming event to convert them from a fusion-incompetent state to a fusioncompetent one. Once the fusion protein is in a fusion-competent state, the structural 


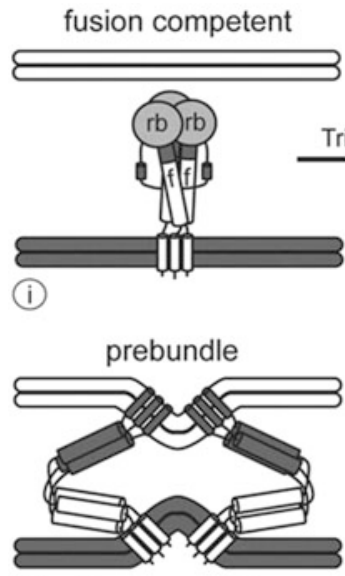

(iv) close apposition

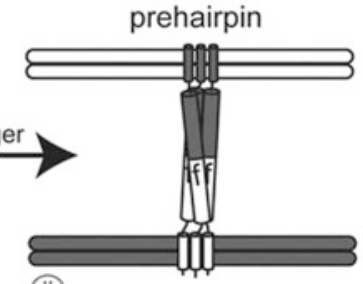

(ii)

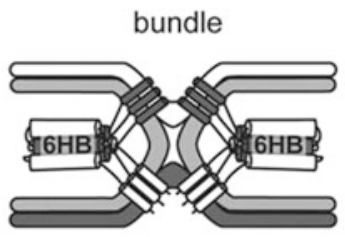

hemifusion

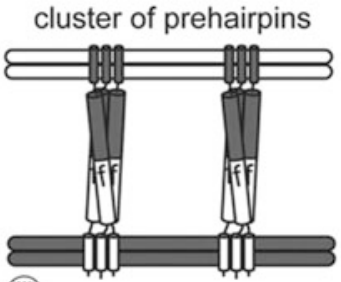

(iii)

trimer of hairpins

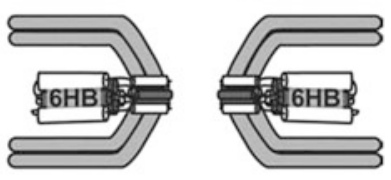

fusion pore

Fig. 2.2 Steps in viral fusion. (i) The viral envelope (bottom) approaches the target membrane (top). The viral fusion protein consists of a receptor binding domain (rb) and a fusion domain (f). (ii) The prehairpin structure embeds into the target membrane. (iii) Several prehairpin trimers cluster together. (iv) The prehairpins begin to fold back to form the prebundle state and bring the membranes close together. (v) Fusion proteins further fold into a six helix bundle (6HB). Lipids in the outer leaflets of the viral and target bilayers mix during hemifusion. (vi) A pore opens between the target membrane and the viral envelope as the fusion proteins become a trimer of hairpins. Source: White et al. [5], Taylor \& Francis Ltd., www.tandfonline.com

rearrangement necessary for exposure of the fusion peptide and its burial into the target membrane is often triggered by some change in environmental conditions. Fusion may be triggered by receptor binding itself, lowering of $\mathrm{pH}$, protease action [6], or a combination of these [4, 7]. Viruses that fuse at the plasma membrane may be triggered by receptor binding or protease activation, while those that fuse within the endosome generally require low $\mathrm{pH}$ and may require other additional cues, such as changes in other ions than protons, or endosome-specific protease exposure.

Despite the diversity in structure and triggering mechanisms, fusion proteins typically follow a common pathway for merging the viral envelope with the host membrane (Fig. 2.2), as described in White et al. [5] and Harrison [8]. After fusion is triggered, the protein rearranges into a prehairpin intermediate (1) with the fusion peptide inserted into the host membrane. While the fusion protein may be found as dimers or trimers on the surface of the virus (2), the prehairpin intermediate consists of a trimer. It is thought that several prehairpin intermediates cluster together then fold back on themselves to bring the membranes close to each other (3). As the prehairpins fold into a six-helix bundle, the membranes are brought close enough that lipids from their outer leaflets are able to mix, creating a structure often referred to as a "stalk" (4). This step is known as hemifusion. Lastly, a pore forms (5) enabling the viral genome to pass through this opening as the fusion proteins form into a stable trimer of hairpins. 
Although all viral fusion proteins studied to date follow this common pathway, much remains unknown about viral entry itself. For example, the dynamics of these fusion steps are not fully understood, the fusion trigger of some viruses remains ambiguous, and developing antivirals to halt virus entry requires further characterization of all of the steps between initial viral contact with the host cell and viral genome release.

Techniques for studying virus entry can be broadly classified as those that examine the entry of a collective group or ensemble of virions and those that track individual virion entry. Ensemble methods provide information on the broader context of entry steps, while single virion imaging provides detailed information on the dynamics of those steps. Ensemble methods include many of the most wellestablished techniques for studying viral entry and may probe overall infection, receptor binding, fusion, or cargo transfer. Single virion imaging techniques can provide mechanistic detail and kinetics for steps that are masked in ensemble methods. In addition, for HIV [9], influenza [10], and Ebola virus [11], most virions that encounter a cell are not involved in productive entry so the ability of single virion techniques to distinguish entry-competent particles from non-competent ones and characterize their individual behavior provides valuable data on heterogeneity in viral populations and its ultimate impact on infection.

The remaining part of the chapter will focus on single particle tracking microscopy techniques compatible with dynamic/temporal data acquisition, their salient features, and how the data generated complement ensemble methods for studying viral entry processes and their intermediate steps and mechanisms.

\subsection{Single Virion Tracking Techniques}

\subsubsection{Enabling Technologies}

Over the past 30 years, microscopy optics, fluorescent labeling strategies, computing power and image processing have enabled the dynamic tracking of individual virions throughout the entry process and the decomposition of their intermediate steps. For some examples, see the following references: [12-18]. In particular, charge coupled device (CCD) cameras combined with advanced microscopy enable single particle resolution [19]. The frame rates of today's cameras dictate temporal resolution of dynamic studies, which can range from a few to hundreds of milliseconds $[20,21]$. In the following sections, the main advances enabling single virion tracking techniques are summarized.

\subsubsection{Microscope Configurations}

Three microscopy configurations are commonly employed in virology research: epifluorescence, total internal reflection fluorescence (TIRF), and confocal 

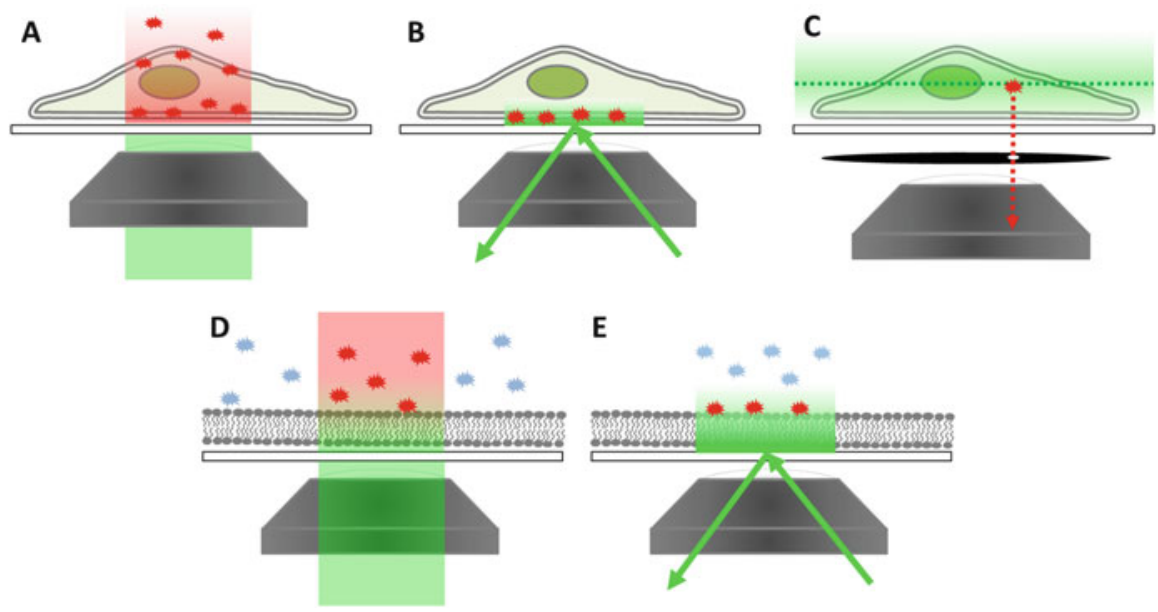

Fig. 2.3 Microscope configurations for viewing virus interactions with cells and biomimetic membrane surfaces. Green color denotes excitation light and red denotes emission light. (a) The epifluorescence configuration illuminates an entire light path through the cell and excites any fluorophores within it, making it impossible to track virions in live cells this way due to the overall background signal. (b) TIRF microscopy illuminates a thin layer near the interface between the glass microscope slide and buffer solution. Cell membranes residing in this zone with fluorescently labeled virions can be visualized as individuals, provided they are far enough apart from each other. (c) Confocal microscopy with a pinhole arrangement can examine specific Z-planes within the cell and block out nearly all background signals from the surrounding media excited by out-of-plane light. Here, the green dashed line denotes the focal plane of excitation, the green gradient denotes out-of-plane light, and the red star and its dashed line arrow indicate only the emission from this fluorophore travel to the camera. (d) Epifluorescence illumination in the biomimetic membrane platform suffers the same poor background issue as whole cells when fluorescently labeled virions are in the bulk. (e) TIRF microscopy enables individual virion visualization bound to the membrane surface without exciting those in the bulk above it

microscopy [22, 23] as illustrated in Fig. 2.3. The epifluorescence configuration (Fig. 2.3a, d) illuminates everything within the field of view. So, unbound virions in the bulk phase or cells with high background autofluorescence result in high noise that obscures signals from individual virions. As a result, epifluorescence is not typically used for single virion tracking.

In the TIRF configuration (Fig. 2.3b, e), only particles within a shallow field are illuminated, eliminating noise from the bulk solution and thereby enhancing the signal-to-noise. This configuration is achieved by setting the incidence angle of the laser to be higher than the critical angle for total internal reflection of the laser light at the glass/water or glass/cell interface, resulting in an exponentially decaying evanescent field that penetrates roughly $100 \mathrm{~nm}$ into the sample [24, 25]. The advantage with this configuration is that a two-dimensional plane can be monitored precisely, enabling the distinction between binding and fusion events of the virions, with appropriate virion labeling (described next). However, no three dimensional tracking information can be obtained; data collection is confined to the interfacial region of 
interest. This configuration is most suitable for examination of virus behavior at biomimetic surfaces like supported lipid bilayers or live cell plasma membranes close to the glass surface.

In the confocal microscopy configuration (Fig. 2.3c), a pinhole optic assists in filtering out background noise while scanning across a sample one Z-plane at a time. Cross sections may be stacked to yield a three-dimensional image, making this configuration suitable for imaging live or fixed cells and observing trafficking of viruses in the cytosol. The disadvantage of this configuration is the difficulty in temporally tracking phenomena in real-time, while simultaneously scanning across slices of the sample and reconstructing the image. Furthermore, exposure to strong light can be toxic to living cells [26]. As technology advances, these drawbacks should subside.

\subsubsection{Virion Labeling}

In all of these microscopy techniques, virions must be labeled to visualize them. Virions are commonly labeled by attaching fluorescent proteins to viral proteins, by incorporating chemical dyes into the virion, or by incorporating quantum dots [27-29]. Here, we focus on fluorescent and chemical labels; for a review of quantum dot techniques we refer the reader to Liu et al. [28]. Both fluorescent proteins and chemical labels have been used to label viral coatings as well as contents. Fluorescent viral protein constructs can be prepared for enveloped [30] or non-enveloped viruses [31,32] and virions are labeled as they are synthesized. Chemical labels, including Alexa dyes, octadecylrhodamine B (R18), and carbocyanine perchlorates (DiD, DiI, or DiO) may be added during virion synthesis or post-production. Some chemical labels, like lipophilic dyes, are only suitable for labeling enveloped viruses while others, like amino-reactive dyes, may be employed with either enveloped or non-enveloped virions [22].

Membrane hemifusion is typically monitored with lipophilic dyes that undergo dequenching when the virion fuses with the target membrane, while pore formation is typically tracked with a dye that can partition into the capsid and then dissipate upon release from the virion [33, 34]. It is also possible to incorporate $\mathrm{pH}$ sensors into the envelope of virions to measure the $\mathrm{pH}$ of the fusion environment [35]. In all cases, care must be taken to ensure that labeling does not adversely impact viral infectivity. This can be easily assessed by conducting cell infectivity assays with labeled virions. In general, these labeling approaches can be optimized to mitigate any significant negative impact.

\subsubsection{Image Processing}

Once the microscopy configuration and virion labeling method have been chosen, image processing assists in extracting information from the images. Today's fast computers and image processing algorithms assist in noise filtering, virion tracking, 
and trajectory mapping, as described in the references that follow. In single virion imaging, noise is always a primary concern, regardless of the microscope configuration. To combat this, several particle detection and image restoration techniques have been developed specifically for single virion tracking [36, 37]. Coordinates of the particles are obtained by scanning filtered images for areas of fluorescence intensity that exceed a certain threshold or fit a particular intensity profile $[38,39]$. The next challenge is obtaining accurate virion tracking from one frame to the next (temporal trajectories). Particle trajectories can be calculated from nearest-neighbor associations [21, 40]. Measurements of virion movement and mean squared displacements are then used to determine whether the virions exhibit directed, normal, or anomalous diffusion [41]. The diffusion type can indicate the type of interactions the virion is having with the surface of the cell or extracellular environment. Tracking frame-to-frame is important in measuring binding residence times as well, and by extension, binding strength characteristics [37]. Once bound, the progression of membrane fusion can be tracked from frame-to-frame using strategies like fluorescence dequenching, where the evolution of the fluorescence signal reports on the merging of membranes, the rate of membrane mixing, and the release of viral genome. Finally, obtaining good statistical data from virion tracking experiments requires collecting data on hundreds of individual virions.

\subsubsection{Experimental Approach}

Single virion tracking may follow virions through the infection process in live cells using confocal microscopy or within an in vitro biomimetic platform using TIRF microscopy. Cell-based virion imaging techniques enable direct visualization of the viral entry pathway and interactions between virions and host cell machinery within the native complexity of the cellular environment. On the other hand, biomimetic platforms utilizing the TIRF configuration enable observation of membrane surface phenomena and can be integrated with tools like microfluidics that allow the user to define and test a tightly controlled environment. This control enables decoupling of factors that may be hard to detangle in vivo. Sections 2.2.2.1 and 2.2.2.2 provide overviews of these two approaches while Sect. 2.3 provides examples of specific implementations of single virion tracking to the investigation of viral entry and contrasts them with ensemble approaches.

\subsubsection{Live Cell Imaging}

In current cell-based fluorescence assays, both virions and cellular components are fluorescently labeled so their interactions can be tracked with multicolor real-time microscopy. Live cell virion tracking can be used to observe cell-cell spread, receptor binding, intracellular trafficking and membrane fusion. Virions may be labeled with fluorescent proteins, chemical dyes, or quantum dots while intracellular 
components are typically labeled using fluorescent proteins. Epifluorescence, TIRF, and confocal microscopy have all been used in live cell single virion tracking. Virions may be tracked in two or three dimensions depending on the microscope configuration, as described above. Certain cell types may be easier to image due to autofluorescence of cellular components [11].

As early as the 1980s, fusion of individual virions at the plasma membrane surface was observed. Virions were labeled with R18, which self-quenches at high concentrations, and dequenching of the R18 upon fusion of the virion with a membrane was detected by a simple fluorescence microscope. Early assays monitored fusion at the plasma membrane of erythrocytes, where fusion of influenza could be triggered by lowering the $\mathrm{pH}[42,43]$.

An important aspect of live cell approaches is that it is possible to inhibit cellular machinery by drug treatment or gene knockout. Such cells can be used in combination with live cell imaging to identify key cellular components that are necessary for virus entry. A review of implementations and insights gained from live cell single virion imaging will be provided in Sect. 2.3. We also recommend the reviews by Brandenburg and Zhuang [14], Ewers and Schelhaas [20], Otterstrom and Van Oijen [22], Sun et al. [23], and Wang et al. [29].

\subsubsection{Biomimetic Platforms}

In early work, perhaps the first, observations of membrane fusion of individual virions to biomimetic membranes was monitored with video fluorescence microscopy $[44,45]$. In this work, planar bilayers were suspended over a small hole in a Teflon sheet, a so-called black lipid membrane (BLM), to serve as the host cell membrane mimic. However, BLMs are fragile and prone to rupture and continued progress using this approach was slow. In recent years, supported lipid bilayers, which are more robust than BLMs, have become more widely used in in vitro single virion tracking experiments. Because these SLB platforms are becoming the backbone of many types of single virion tracking experiments, it is worth describing them in some detail here.

A supported lipid bilayer is a planar, single bilayer, typically self-assembled by rupturing liposomes at the surface of hydrophilic silica surfaces like glass microscope slides. For reviews of supported lipid bilayer technologies, we encourage the reader to consult Sackmann [46], Tanaka and Sackmann [47], and Castellana and Cremer [48]. These supported lipid bilayers act as mimics for cellular membranes and the compatibility of these bilayers with flat glass surfaces makes them ideal for coupling to microscopy techniques. Additionally, supported bilayers may be assembled within a flow cell or microfluidic device, which enables the exchange of buffers and, consequently, the precise control over the binding and fusion environment during single virion tracking microscopy. The composition of these bilayers is highly tunable, ranging from the simplest lipid components, to recapitulating the complexity of the plasma cell membrane of specific cell types (Fig. 2.4). 


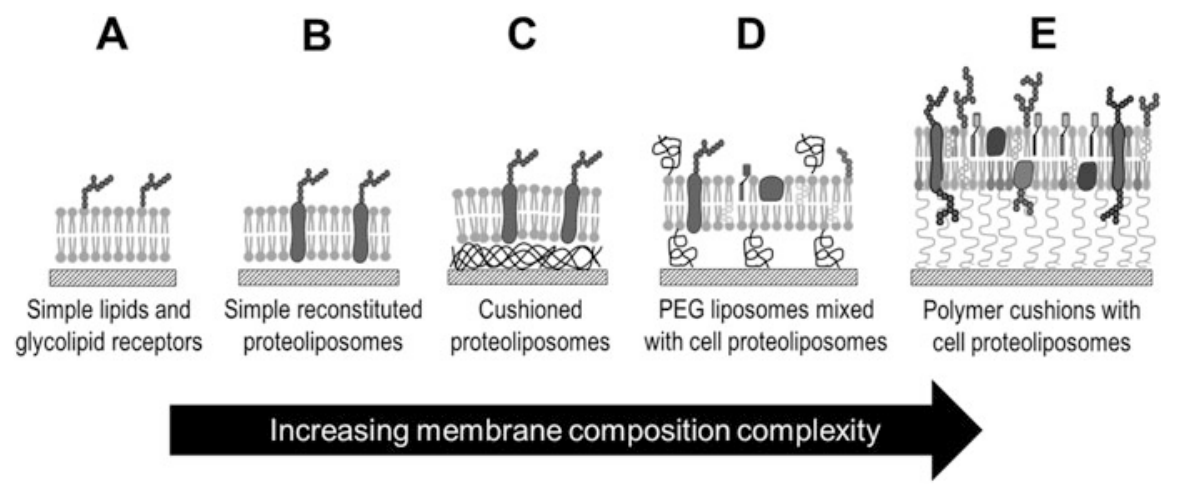

Fig. 2.4 Supported lipid bilayers (SLBs) and their increasing complexity and features. (a) A simple SLB with glycolipid receptors. (b) A SLB made from reconstituted lipids and protein receptors. (c) Cushioned SLB to enhance protein receptor mobility. (d) Mixed liposome and cell-derived SLB containing polyethylene glycol cushions. (e) Plasma membrane-derived SLB on polymer cushion

Initial studies employed purely lipid bilayers with glycolipid viral receptors $[12,33,34,49]$. More recent work has used reconstituted proteoliposomes that contain protein receptors [50]. There has also been progress in using composite membranes made from cell-derived membrane components mixed with PEGylated liposomes to engender the SLB with both biologically relevant material (receptors, etc.) and a built-in cushion to maintain constituent mobility [51, 52]. Other work has demonstrated the ability to form bilayers from cell plasma membrane blebs as a way to incorporate transmembrane proteinaceous receptors and complete native cell materials into planar geometries [13, 53, 54]. The incorporation of transmembrane proteins greatly expands the range of viruses that can be studied with single virions tracking techniques [13].

Notably, the simplest lipid-only bilayer on glass is roughly $4 \mathrm{~nm}$ thick and sits above a thin layer of water on the order of a nanometer thick [55, 56]. This feature enables the two-dimensional mobility of lipids within the bilayer necessary for membrane fusion, but mobility is also a key property for allowing receptors to rearrange to permit multivalent binding interactions, as they do in live cell membranes. Mobility of protein receptors, particularly those with transmembrane domains, can be a challenge in these platforms if the water gap is insufficient for limiting interaction between the protein and the glass support. To overcome this challenge, various cushions, such as polyethylene glycol (PEG) [52], bovine serum albumin, dextran [33, 57], or polyelectrolyte brushes [54], have been placed between the bilayer and the supporting surface to improve protein mobility [58].

It is also possible to form supported lipid bilayers that mimic the viral membrane instead of the host membrane and conduct experiments in the opposite configuration. Here, binding and fusion is studied by monitoring liposomes decorated with host cell receptors interacting with the planar virus-like bilayer containing embedded viral proteins [59-61]. Such an arrangement could be used for screening applications of antivirals that target entry processes, without the need for live virus or pseudotyped particles. 
In summary, biomimetic platforms enable a level of environmental control that cannot be attained in live cell particle tracking techniques. First, there is a degree of control over the host cell membrane mimic's composition that is difficult to alter in live cells. Second, in these platforms, the buffers in contact with the virus can have a defined composition and the experimenter controls the timing and order of exposure to proteases, $\mathrm{pH}$, or any other component of interest to the virus. But perhaps the most salient feature of this experimental approach is that these platforms allow detailed examination of the binding and membrane fusion process and gathering of dynamic data from these processes. However, the two-dimensional, in vitro nature of these platforms make them unsuitable for measuring cytoskeletal involvement in entry. Thus, to obtain the most complete information about the infection process, combining data from complementary approaches using live cells and biomimetic platforms is an excellent strategy.

\subsection{Applications of Single Virion Tracking and Complementary Ensemble Approaches}

In the following sections we describe how single virion tracking has been applied to investigate different steps in virus entry. We also include overviews of a selection of ensemble methods to appreciate the synergy between the data collected by the different techniques in providing a complete description of virus entry. Table 2.1 provides a quick reference of techniques and the data that can be obtained in each approach for each entry stage.

\subsubsection{Tracking Extracellular Movement of Virions}

There are two scales of transport to be observed during virus spread and infection. On the larger scale is the transport and spread of virions between neighboring cells. Also of interest is the smaller-scale tracking of an individual virion on a cell plasma surface before it is internalized by that particular cell. In the following sections, experiments at each scale will be described with selected examples and references.

\subsubsection{Tracking Virion Movement Between Cells}

Tracking virion movement in the in vivo environment has revealed various avenues of virus spread to surrounding cells. The predominant transport mechanisms of virus spread between cells are: (1) virions freely diffusing through the extracellular environment to neighboring cell surfaces, or (2) spreading to neighboring cells through direct transmission across adjoining membranes. For the first mechanism, 
Table 2.1 Comparison of single virion and ensemble methods for studying particular viral entry steps, including key features of each method

\begin{tabular}{|c|c|c|c|}
\hline \multirow{2}{*}{$\begin{array}{l}\text { Virus entry } \\
\text { step }\end{array}$} & \multicolumn{2}{|l|}{ Single virion tracking } & \multirow{2}{*}{$\begin{array}{l}\text { Ensemble } \\
\text { methods }\end{array}$} \\
\hline & Live cell & Biomimetic & \\
\hline $\begin{array}{l}\text { Extracellular } \\
\text { transport }\end{array}$ & $\begin{array}{l}\text { - Direct cell-cell spread } \\
\text { - Extracellular diffusion }\end{array}$ & $\begin{array}{l}\text { - Movement through } \\
\text { mucosa }\end{array}$ & \\
\hline $\begin{array}{l}\text { Cell-surface } \\
\text { trafficking }\end{array}$ & $\begin{array}{l}\text { - Cytoskeletal interaction } \\
\text { - Movement toward entry site }\end{array}$ & $\begin{array}{l}\text { - Diffusion, rolling, and } \\
\text { rocking along surface } \\
\text { - Bilayer composition } \\
\text { - Bilayer fluidity }\end{array}$ & \\
\hline Binding & - Colocalization with receptor & $\begin{array}{l}\text { - Attachment/detach- } \\
\text { ment rates } \\
\text { - Bilayer composition } \\
\text { - Bilayer fluidity } \\
\text { - Receptor mobility } \\
\text { - Adhesion- } \\
\text { strengthening }\end{array}$ & $\begin{array}{l}\text { QCMD } \\
\text { Coflotation } \\
\text { ELISA } \\
\text { SPR } \\
\text { TEM }\end{array}$ \\
\hline Internalization & $\begin{array}{l}\text { - Clathrin dependence/indepen- } \\
\text { dence } \\
\text { - Internalization timescale } \\
\text { - Cytoskeletal interaction }\end{array}$ & $\mathrm{n} / \mathrm{a}$ & $\begin{array}{l}\text { IFA } \\
\text { TEM }\end{array}$ \\
\hline Fusion & $\begin{array}{l}\text { - Differentiate plasma membrane } \\
\text { fusion from endosomal fusion } \\
\text { - Escape from early vs. late } \\
\text { endosomes }\end{array}$ & $\begin{array}{l}\text { - Bilayer composition } \\
\text { - Bilayer fluidity } \\
\text { - Viral fusion environ- } \\
\text { ment } \\
\text { - Timing/sequence of } \\
\text { fusion triggers } \\
\text { - Hemifusion and pore } \\
\text { formation rate constants } \\
\text { - Number of rate- } \\
\text { limiting fusion steps } \\
\text { - Acid stability }\end{array}$ & $\begin{array}{l}\text { TEM } \\
\text { Syncytia for- } \\
\text { mation } \\
\text { Bulk solution } \\
\text { fluorescence } \\
\text { Infectivity } \\
\text { BlaM release }\end{array}$ \\
\hline $\begin{array}{l}\text { Intracellular } \\
\text { trafficking }\end{array}$ & $\begin{array}{l}\text { - Cytoskeletal interaction } \\
\text { - Extra- and intra-nuclear } \\
\text { movement }\end{array}$ & $\mathrm{n} / \mathrm{a}$ & IFA \\
\hline
\end{tabular}

Acronyms: QCMD Quartz crystal microbalance with dissipation, ELISA Enzyme-linked immunosorbent assay, SPR Surface plasmon resonance, TEM Transmission electron microscopy, IFA immunofluoresence assay, BlaM Beta lactamase

the mean-squared displacement of virions over time is used to classify their motion as diffusive or sub-diffusive through the extracellular environment. For example, live cell single virion tracking of adeno-associated viruses [17] and simian virus 40 virus-like particles [62] indicates that particles undergo normal diffusion in the extracellular environment. Adeno-associated viruses slow down when in the vicinity of a cell, and touch the cell membrane multiple times before penetrating the cell [17]. In contrast, HIV follows the second mechanism and preferentially transmits directly from one neighboring cell to another through virological synapses rather than transmission by extracellular diffusion [63-65] Some viruses exploit cytoskeletal components to facilitate transport from one cell to another. Vaccinia virus, for 
example, induces the formation of actin protrusions from the cell surface and is transported along these to spread from cell to cell [66]. Looking at viral transport over a longer distance scale, single virion imaging has shown that pseudorabies virus is able to spread from the site of infection to the peripheral nervous system ganglia for replication then back along axons to reseed the initial infection site [67]. In vitro experiments have been used to study how respiratory mucosa hinders the ability of pseudorabies virus to cross into the epithelium, revealing that both size and charge interactions are important [68].

\subsubsection{Tracking Virion Movement on Live Cell Plasma Membranes}

There are multiple strategies for observing lateral viral movement along the plasma membrane of a live cell. One method is labeling the core of virions and cellular actin (to delineate the border of cells) and track virion movement along the periphery of the cell [69]. Another method is to label the viral membrane and look at diffusion on top of membrane until the virion overlaps with an endocytosis site [70]. A few examples of virion movement that have been studied this way are as follows. Simian virus 40 undergoes actin independent diffusive movement on the cell membrane until it reaches caveolae [71]. Dengue virus similarly freely diffuses on the membrane until it reaches an existing clathrin-coated pit [70]. Murine polyoma virus-like particles also freely diffuse at first, then become confined and follow actin-directed trajectories afterwards [72]. Vaccinia bound to filopodia have been observed to move towards the cell body along the plasma membrane [73].

Some viruses employ a mix of two mechanisms, free diffusion and directed motion. Some examples of this type of movement are as follows. After binding to filopodia, murine leukemia virus, avian leucosis virus, vesicular stomatitis virus, and rabies virus appear to "surf" on top of the membrane via actin and myosin II driven transport towards entry sites [69, 74]. Similarly, adenovirus binds its receptor then drifts along the cell surface with the assistance of actin and myosin II $[75,76]$. Coxsackievirus has been shown to bind on the apical surface of epithelia, which then triggers cytoskeletal rearrangement that transports the virus to the site of viral entry, the tight junctions [77]. Finally, influenza virus appears to undergo actindirected motion in the area near its initial binding site on the cell surface $[10,78]$.

\subsubsection{Tracking Virion Movement on Biomimetic Cell Surfaces}

In the in vitro environment of supported lipid bilayer platforms, virions diffusing along the bilayer follow a continuous trajectory, whereas those that bind, detach, and rebind elsewhere on the surface "appear" and "disappear" under TIRF microscopy. These modes of transport are easily distinguished from each other using this microscopy approach [79]. Supported lipid bilayers have an advantage over live cells for certain types of studies because of the ability to tightly control composition, receptor density and mobility, and surface geometry and heterogeneity. For example, 
supported lipid bilayers have been used to observe sliding and tumbling of quantum dot-labeled simian virus 40 virus-like particles on bilayers containing low concentrations of GM1 and back-and-forth rocking at high receptor concentrations [36]. However, because lipid bilayers do not contain the full cytoskeletal network of cells, it is possible that virion motion in these platforms could be different from their motion in vivo.

\subsubsection{Binding}

Studies of virus binding kinetics and determination of binding strength are often carried out in in vitro assays, either by monitoring many single virion events or following ensemble behavior of a population. In this section, we describe these approaches and highlight some selected studies that illustrate their utility.

\subsubsection{Single Virion Tracking of Binding}

Direct observation of many individual virion interactions with supported lipid bilayers can be used to measure receptor binding and detachment rates, multivalent avidity characteristics, and equilibrium binding constants. TIRF microscopy is the most common method used in monitoring individual virions binding to biomimetic membranes because it clearly distinguishes labeled virions that are bound to the lipid bilayer from unbound virions in the bulk solution (Fig. 2.5). In this experimental approach, the residence time of bound virions can be collected for each individual

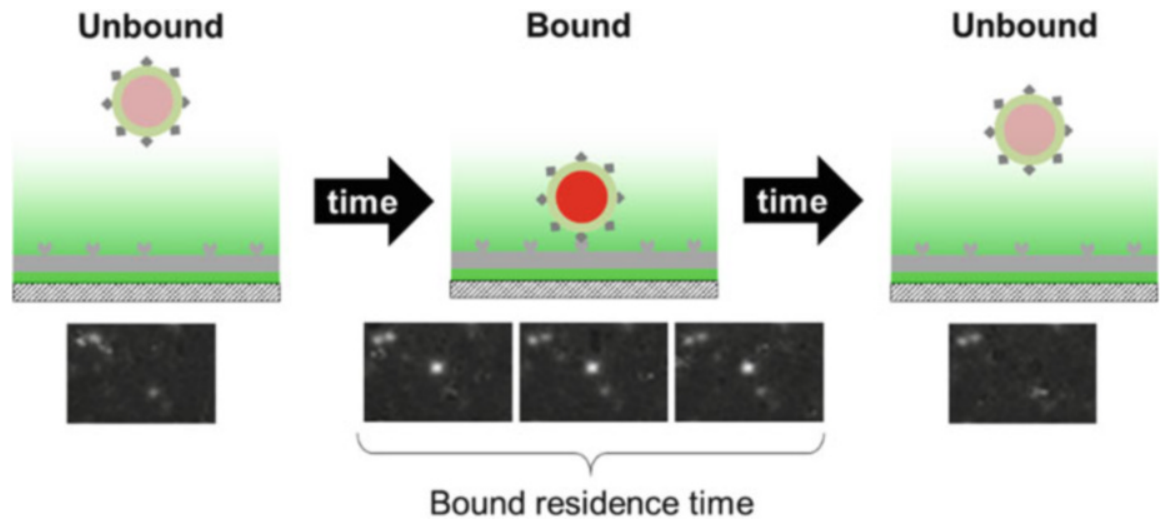

Fig. 2.5 TIRF microscopy visualizes virions bound on the membrane surface (gray) within a $100 \mathrm{~nm}$ deep evanescent wave (green). Fluorophores in unbound virions are not excited by the evanescent wave, while virions bound to the bilayer are illuminated, denoted here by the bright red color in the center cartoon. Residence times can be determined by the number of frames the virion remains observable, as shown in the images below the cartoons, before the virion unbinds 
virion. As experimental conditions change, shifts in residence times can be monitored. From this data, binding characteristics can be quantified.

Initial work monitoring nanoparticle binding to supported bilayers and surfacetethered vesicles demonstrated the advantage of using TIRF microscopy in this application. Here, a useful approach, equilibrium-fluctuation-analysis, was developed to quantify apparent kinetic rate constants of carbohydrate-bearing particles with carbohydrate presenting SLBs [80]. This analysis was then extended to studies of virus-like particles $[49,81]$ and live virions [81] interacting with glycosylated bilayers to provide new insight into virus attachment to cell surfaces and applications in biosensing [82]. The kinetics of particle detachment [83] can also be studied in these platforms, as can multivalent binding behavior [62, 84]. Such studies can reveal changes in binding behavior that promote viral attachment. For example, both influenza and canine parvovirus undergo "adhesion-strengthening" where the longer a virion is bound, the more strongly it adheres to the bilayer [37, 85]. Overall, these platforms are convenient for gathering insight on this critical virus entry step and how it depends on the host cell surface.

One advantage of this platform is the tunability of the bilayer compositions and heterogeneity. For example, single particle binding studies have revealed the importance of microdomains in binding of norovirus-like particles, which preferentially bind the edges of glycosphingolipid-enriched domains [49]. Later it was also shown that HIV particles prefer to bind at the edges of cholesterol-rich lipid domains that were reconstituted in supported bilayers [86, 87]; however, observing this preference in live cells due to the small scale and dynamism of lipid rafts is difficult, illustrating the power of using an in vitro system for such studies. Focusing further on the receptors themselves, TIRF microscopy has also been used to measure the affinity of HIV glycoprotein 120 for the glycosphingolipids galactosyl ceramide, glucosylceramide, lactosylceramide and $\alpha$-hydroxy glucosylceramide in SLBs $[88,89]$. The affinity of glycoprotein 120 for these lipids is roughly 5 times lower than its affinity for CD4 [90].

The importance of studying the binding step is that the tropism of a virus is strongly tied to its ability to bind various receptors. A nice example, illustrating the power of combining single virion binding measurements with cell infectivity studies, clearly showed that a single mutation in the canine parvovirus capsid is able to alter binding to dog and raccoon transferrin receptors and completely change the tropism of the virus [85].

\subsubsection{Ensemble-Based Approaches for Studying Virion Binding}

Binding can be monitored using ensemble approaches that monitor the overall change in an aggregate signal from many virions interacting with a target surface. The simplest manner to measure virion binding to a particular host cell receptor is the cofloatation assay. In these assays, viral particles or purified fusion proteins are labeled with a probe and mixed with liposomes containing the receptor for the virus. After the virus has bound, the mixture can then be added to a sucrose gradient and 
fractionated. The fractions are analyzed with PAGE or Western Blot to determine under which conditions the virus and liposomes comigrate or cofloat [91, 92]. Altering the composition of the liposomes can be used to determine what lipids and proteins the virus binds to. This assay is able to probe virus-receptor interactions but does not provide information on binding kinetics. An additional limitation is that it may be difficult to purify or prepare liposomes containing the receptor, particularly if it is a transmembrane protein.

Some ensemble viral binding assays, like enzyme-linked immunosorbent assay (ELISA) or glycan arrays, immobilize proteins, carbohydrates, or glycans on a rigid surface. These arrays do not preserve the structure, complexity, or two-dimensional fluidity of cellular membranes, which may limit accurate assessment of binding avidity. However, they can be useful for rapidly identifying binding partners in screening, for example, potential tropism changes [93].

Measurements of real-time binding and desorption can be assessed using techniques like surface plasmon resonance (SPR) [94] and quartz crystal microbalance with dissipation (QCM-D) [49, 95]. SPR uses changes in refractive index to report the binding behavior, while QCM-D uses a shift in resonance frequency to report virus interaction. In both approaches, biomimetic membranes can be used to preserve many properties of the host cell surface, including integration of the receptor. Kinetic analysis of binding with these techniques requires two experimental phases to decouple binding and unbinding of virions. In the first phase, virions are added to a biomimetic surface and bind to the receptors. In this way, an "on" rate can be obtained. In the second phase, a virus-free buffer is added and the dissociation of the virus from the receptor is monitored. In this arrangement, an "off" rate can be obtained.

It should be noted that averaged data from many single virion tracking binding/ unbinding events should match the ensemble results generated with SPR or QCM-D. However, direct imaging with single virion tracking allows collection of a richer set of data for on and off rates simultaneously because each particle trajectory is captured [37]. Furthermore, by having the signature of each individual virion's binding behavior, heterogeneities in the virus population or membrane surface can be identified, which can then be compared to infection trends to understand how population dispersity impacts infection [96].

\subsubsection{Internalization}

Internalization, or the uptake of the virus particle into the cytosol, can be assessed either with live cell imaging or in fixed cells through immunofluorescence imaging. 


\subsubsection{Live Cell Imaging}

In live cell virion tracking, cellular components, like clathrin and caveolin, can be fluorescently labeled and colocalization of these components with virions enables determination of whether the primary means of viral entry is through clathrin-dependent endocytosis, caveolin-dependent endocytosis, or a clathrin/caveolin independent uptake mechanism. When tracking labeled virions on live cells, rapid unidirectional motion indicates that particles have been internalized [70, 78, 97].

Live-cell tracking has revealed myriad information about virus internalization, including identifying viral dependence on clathrin or caveolin for uptake as well as the ability of viruses to promote their own uptake. For example, Reovirus induces the formation of clathrin-coated pits for uptake [97]. Simian virus 40 has the ability to induce actin rearrangement to further promote its own internalization whereas echovirus 1 does not $[71,98]$. Clathrin-mediated endocytosis is utilized for the uptake of many viruses including Australian bat lyssavirus [99], HIV [100], infectious hematopoietic necrosis virus [101], and rabiesvirus [74]. Other viruses are caveolinindependent or use macropinocytosis. For example, mouse polyomavirus is also delivered to early endosomes by a caveolin independent pathway [102]. Adenovirus 2 enters the cell viaboth clathrin dependent and independent endocytosis and triggers macropinocytosis [103-106]. Still other viruses have been shown to be agile in their internalization route, for example, in the absence of caveolin, simian virus 40 can exploit a clathrin/caveolin independent pathway [107]. Studies have shown that bound influenza virions have the ability to induce the formation of clathrin-coated pits, but can also enter in a clathrin/caveolin independent manner [78]. Influenza is then preferentially sorted into a population of early endosomes that quickly matures [108].

\subsubsection{Immunofluorescence Imaging}

To monitor virus entry without live cell particle tracking, infected cells can be fixed and imaged with an immunofluorescence assay. Permeablized cells can be probed with antibodies against viral proteins, and cytoskeletal elements, or endocytosis markers. Colocalization of viral particles and cellular components can then reveal the general entry pathway of the virus [109-111]. Cells can be fixed at various time points after infection to determine the general time course of entry $[112,113]$. This method provides snapshots of the viral entry process because the cells are fixed before imaging, but it requires less specialized microscopes and cameras than livecell imaging. 


\subsubsection{Intracellular Trafficking}

For viruses that are internalized, live-cell fluorescent imaging can provide insight into how viruses use cellular machinery, such as the cytoskeleton or microtubules, to propel their movement within the cell. One common approach to determining if cytoskeletal elements are involved is to compare the speed and shape of virion trajectories in the presence and absence of cytoskeletal inhibitors such as nocodazole, and cytochalasin D [114]. This strategy has been employed to determine that reovirus movement after endocytosis is microtubule-directed [114]. Microtubules are involved in the cytosolic movement of Adeno-associated virus type 2 [115], HIV [30, 116] infectious hematopoietic necrosis virus [101], rabies virus [74], In contrast, polio movement inside cells is actin dependent, but microtubule independent [117]. Adenovirus interacts with minus-end dynein and a plus-end directed factor to traffic along cytoplasmic microtubules [118]. Influenza in endosomes undergoes unidirectional dynein-directed translocation to the perinuclear region followed by intermittent back-and-forth microtubule-dependent motion within the perinuclear region prior to virion fusion with endosomes [10].

In addition to investigating movement towards the nucleus, live-cell single virion tracking has been used to monitor movement within the nuclear region. Adenovirus utilizes microtubules for movement within the cell, but detaches from them when the virions reach close proximity to the nucleus [119]. HIV cores move toward the nucleus with a microtuble- and actin-dependent motion; within the nucleus, the motion is slow and diffuse [100, 116, 120]. HIV RNA alone moves through the cytoplasm by diffusion [121]. After reaching the nucleus, HIV pre-integration complexes target areas of decondensed chromatin [122]. For influenza, genes are transported to and within the nucleus by diffusion [123].

Intracellular movement of virions is not necessarily mediated by spike or capsid proteins alone; for herpes simplex virus, the inner tegument proteins promote movement along microtubules and are necessary for movement away from the cell body along axons [124-126]. An alternative method is to use immunofluorescence assays of fixed cells to obtain snapshots of intracellular virion trafficking, including what cytoskeletal components are involved [127, 128]. These do not allow for the tracking of individual virion trajectories and are more limited in temporal resolution than live cell virion tracking, but require less specialized equipment.

\subsubsection{Fusion}

Membrane enveloped viruses must fuse their membrane with the host membrane to deliver their genome to the cytosol for replication. Fusion can occur either at the plasma membrane surface or in endosomes after the virion is internalized. Fusion can be monitored in both live cells and in in vitro platforms. Each approach has 
advantages and disadvantages, and some examples of how these experiments are conducted follow next.

\subsubsection{Tracking Fusion in Live Cells}

Viral fusion at the plasma membrane can be differentiated from fusion within endosomes in live cells. To do so, the viral contents can be labeled with a diffusible content marker while the envelope is labeled with an acid-stable lipophilic dye. If fusion occurs at the plasma membrane, both fluorescent markers will seem to disappear because they will be diluted into the plasma membrane and cytosol. If fusion occurs within an endosome, the viral content marker will disappear as it is released into the cytosol and diluted, but the lipid marker will continue to appear bright as the dye mixes into the relatively small endosomal membrane [129]. This approach has been used to show that HIV can undergo full fusion inside endosomes while fusion at plasma membrane is halted at the lipid mixing step. However, this may be cell-type dependent; HIV content release from plasma membrane fusion was observed for U87 cells but not JC5.3 or HOS cells [130]. The ability to detect viral fusion in live cells within the endocytic pathway often relies on labeling virions with quenched amounts of dye. Colocalization of dequenching virions with labeled cellular components, such as clathrin or Rab proteins, can reveal whether fusion occurs in early or late stage endosomes. This approach has been employed in the study of influenza virus, which fuses in early endosomes, revealing that the virus is able to enter a clathrin-dependent manner as well as a clathrin and caveolin independent fashion, and viral fusion can occur in both pathways [78]. In macrophages, HIV undergoes fusion in Rab5A positive endosomes [100]. Fusion of Dengue virus [70] and Ebola virus [11] colocalizes with Rab7, a marker of late stage endosomes. Alternatively, endosomal fusion may be mimicked by binding virions to the plasma membrane then lowering the extracellular $\mathrm{pH}$. This method of acid-induced endosomal bypass has been employed to characterize avian sarcoma and leukosis virus fusion behavior [131].

Viral fusion can also be monitored by observing the release of fluorescent viral cargo. Avian sarcoma and leukosis virions labeled with fluorescent cargo and an envelope $\mathrm{pH}$ sensor showed little correlation between endosomal $\mathrm{pH}$ and fusion lag time [132]. However fusion lag time and pore size did vary with surface receptor and endosome type, indicating that endosomal composition may modulate fusion $[35,132,133]$. In the case of vesicular stomatitis virus, cytoplasmic nucleocapsid release does not necessarily immediately follow fusion. VSV has been shown to undergo fusion between the early and late endosome stage [134].

\subsubsection{Tracking Fusion in Biomimetic Platforms}

With the lipid bilayer platform, hemifusion and pore formation can be observed within the same particle by dual-labeling the viral envelope and contents with 


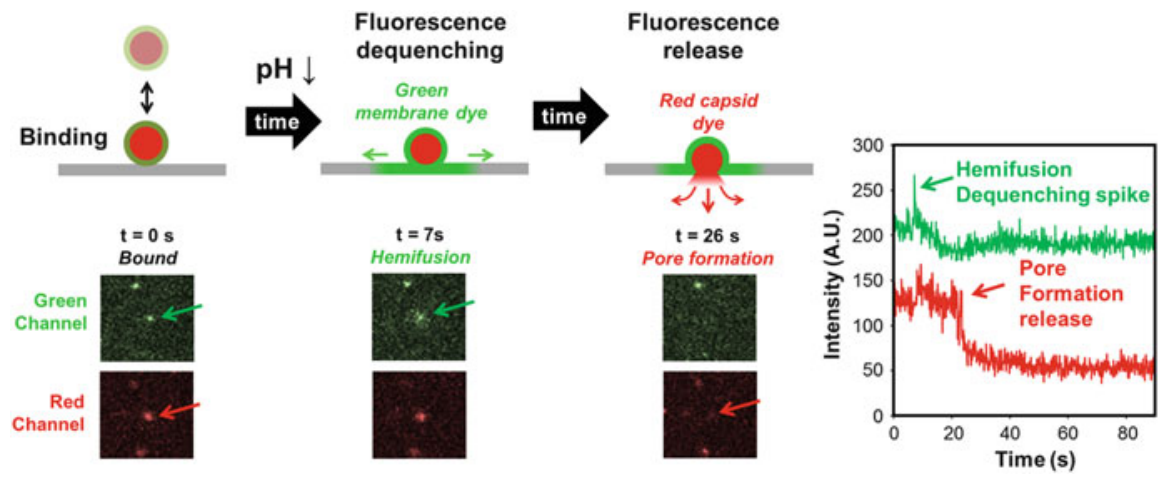

Fig. 2.6 Fusion and intermediate steps can be tracked by a dual-labeling approach. Virions first bind their receptor within the supported lipid bilayer (gray) in the evanescent wave (not shown here) of TIRF. After a trigger (such as a $\mathrm{pH}$ drop shown here at $t=0$ ) membrane fusion occurs between the virion membrane, labeled with a green fluorophore, and the unlabeled supported bilayer. Fluorescence dequenching during fusion indicates hemifusion. Finally, a fusion pore is formed and the internal capsid fluorophores (red) are expelled across the supported bilayer. The plot to the far right shows the intensity change for the virion highlighted by the arrows in the images to the left

different colors (Fig. 2.6). By using a flow cell or microfluidic device, this platform also enables control over the timing of fusion trigger(s) or other environmental changes within the viral environment.

A common fusion trigger is a drop in $\mathrm{pH}$. To trigger fusion, acidic buffer can be passed over the bilayer inside a microfluidic device. Incorporation of $\mathrm{pH}$ sensitive dye into the bilayer enables detection of the time at which bound virions encounter the acid [33]. Alternatively, ultraviolet light can be used to "uncage" protons from $o$ nitrobenzaldehyde in solution to rapidly acidify the bilayer and virions [12]. Both of these methods enable measurement of the lag time between exposure to a fusion trigger and the onset of hemifusion. By analyzing this lag time for hundreds of individual fusion events, the rate constants of hemifusion can be calculated. Pore formation can be monitored by particles also containing internal capsid dyes. Monitoring the drop in signal of this co-localized fluorophore reports the opening of the fusion pore.

If there is a single rate liming step, the distribution of lag times will follow a simple exponential decay, with the decay constant corresponding to the rate constant of that limiting step. If there are multiple rate liming steps, the lag time distribution will rise and decay [135]. A simple approach to quantifying the kinetics of hemifusion and pore formation is fitting the cumulative distribution of fusion events to a convolution of Poisson processes with the equation:

$$
P=\int_{0}^{t} \frac{k^{N} t^{N-1}}{\Gamma(t)} e^{-k t} d t
$$


where $P$ is the probability of a virion being in that state (hemifused or pore forming) at time $t$ after the fusion trigger has been added and $\Gamma(t)$ is the gamma distribution function. This fit yields $k$, the rate constant of that step, and $N$, the number of stochastic rate limiting events governing the kinetics of that step [33]. If there is only one rate-limiting step $(N=1)$, the above equation simplifies to a single exponential decay. As the number of rate-limiting steps increases, more events must be observed to accurately calculate $N$. For processes with three steps or fewer, 50 events is sufficient to calculate $N$ with a standard deviation of 1 [15]. There are other more complex methods for fitting lag time distributions that may capture more of the details of hemifusion [136].

Viruses with Class I, Class II and Class III fusion proteins have been studied at the single virion level with SLBs. The kinetic analysis described here has indicated that influenza virus hemifusion is controlled by three rate-limiting steps while the kinetics of pore formation is governed by a single step [33]. Chikungunya virus also has three-rate limiting steps governing hemifusion [137]. For West Nile virus, hemifusion has one or two rate-limiting steps, depending on the $\mathrm{pH}$ [138]. Vesicular stomatitis virus hemifusion also has multiple rate-limiting steps at higher $\mathrm{pH}$ and a single rate-limiting step at low $\mathrm{pH}$ [139].

While it cannot be assumed that the kinetics obtained from this method reflect the actual reaction rates within a cell, comparison of these rates under different conditions, such as different bilayer compositions, $\mathrm{pH}$, or viral strains, can yield valuable insight. The ability to manipulate the composition of supported lipid bilayers has been used to determine that anionic lipids are essential for vesicular stomatitis virus fusion and that the lag between hemifusion and pore formation is shortened in the presence of bis(monoacylglycero)phosphate, a lipid found in late endosomes [57]. Precisely controlling the triggering $\mathrm{pH}$ has revealed that influenza virus requires a lower $\mathrm{pH}$ to trigger fusion than Sindbis virus [34], suggesting that it fuses later in the endocytic pathway. While the rate of influenza X-31 virus hemifusion increases at lower $\mathrm{pH}$ [33], the rate of Brisbane is much less $\mathrm{pH}$ dependent [140]. The rate of pore formation for influenza virus is $\mathrm{pH}$ independent. Multiple influenza hemagglutinin trimers are involved in fusion [141], although not all are active participants [142, 143]. This platform is able to detect differences in the acid stability and fusion behavior of different strains and reassortants of influenza, which is tied to their tropism [140,144]. This platform can also be used to measure the number of antibodies required to neutralize fusion of a single virion [145]. Figure 2.7 provides a summary of the flexibility, the biomimetic fusion assay and the kinds of insight that has been gained from these tunable assays. With the advances in supported bilayer complexity and fabrication, these platforms can also be used to study viruses that bind proteinaceous receptors, such as feline coronavirus [13].

Finally, given the highly-defined nature of these platforms, viruses that do not have a known fusion trigger or receptor might be difficult to study, because each component must be intentionally added to the platform. However, because SLBs can be formed in a microfluidic device, it should be possible to formulate a high- 


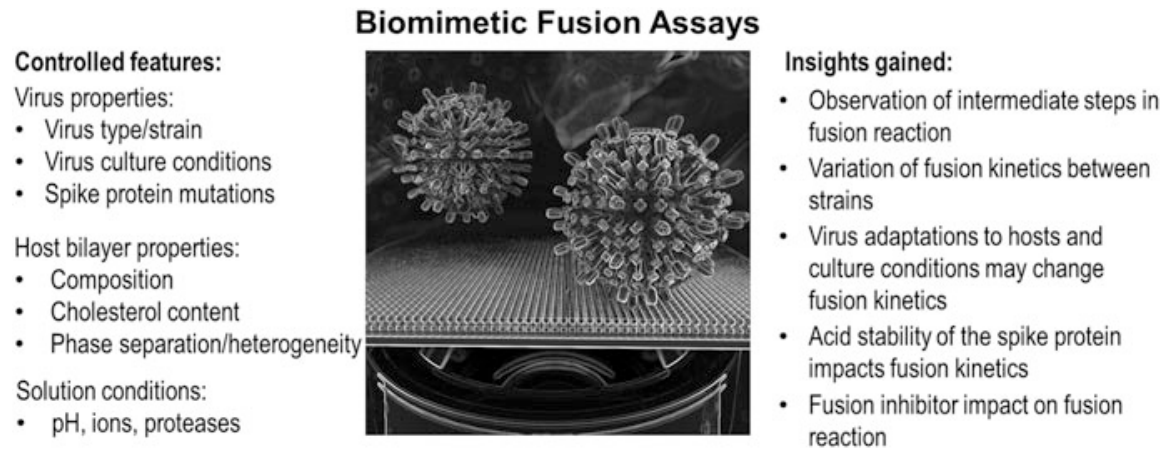

Fig. 2.7 Features that can be easily controlled in biomimetic fusion assays. In combination with a high throughput approach, these conditions (left) can be evaluated to provide new insight into virus fusion. (Right) Examples of the kinds of insight that can be gained with a biomimetic assay that isolates the fusion reaction from other virus entry steps

throughput screen for possible fusion triggers or binding partners with this configuration.

\subsubsection{Ensemble Approaches for Studies of Fusion}

A common method to study fusion behavior is cell-cell fusion assays, where fusion between target cells expressing the receptor for the virus and effector cells expressing the viral fusion protein is monitored. When the viral fusion protein is triggered, for example by lowering the $\mathrm{pH}$, the cells fuse to each other, leading to clusters of multiple nuclei surrounded by a single cell membrane [146]. These clusters are known as syncytia. Lipophilic and aqueous dyes can be used to label the membrane and contents of the effector cell, providing readouts for lipid mixing or pore formation. To isolate the hemifusion step, fusion can be triggered then arrested by quickly cooling the cells to $4{ }^{\circ} \mathrm{C}[147,148]$. This rapid-cooling approach has been used to determine that hemifusion of avian sarcoma and leukosis virus requires low $\mathrm{pH}$, but expansion of the fusion pore does not [148]. As an alternative to monitoring pore formation by observing the transfer of intracellular fluorescent cargo from effector cells to target cells [149], whole cell patch-clamp electrical measurements can be used [150]. In this configuration, a pipette connected to an electrode and amplifier pierces the membrane of the effector cell. The voltage across the membrane can be manipulated and the resulting current measured. During cellcell fusion, the cell surface area increases as the membranes merge, resulting in an increase in membrane capacitance. Such measurements can also allow for estimation of fusion pore size [151].

While syncytia assays do not require viral particles or specialized equipment, making them easy to carry out, there are some limitations. Syncytia form over the course of hours, so this technique is not suitable for obtaining kinetic data 
[152]. Furthermore, the extracellular environment can differ substantially from the endosomal environment, which may create artifacts when using this technique to study viruses that typically fuse within the endocytic pathway. In this approach, any impact of the virion size or shape on fusion is not captured.

In bulk fusion assays, viral particles are fluorescently labeled, then they are mixed with liposomes in a cuvette and the fluorescent signal of the solution is measured by fluorimetry as fusion triggers are added. In one labeling approach, particles and/or liposome membranes can be labeled with fluorescence energy resonance transfer (FRET) pairs. If fusion occurs, FRET will stop as the pairs become separated, and the fluorescence signal will change accordingly [153]. In the second labeling approach, particle membranes are labeled with a single quenched fluorescent marker [154]. Upon fusion with a liposome, the quenched fluorophores will become diluted and dequench, causing a marked increase in fluorescence.

In a third approach, the release of viral cargo can be detected by measuring $\beta$-lactamase (BlaM) activity. In this type of assay, target cells are loaded with a dye containing a $\beta$-lactam ring and a FRET pair. Chimeras of viral core proteins and $\mathrm{BlaM}$ are incorporated into virions. If virions are able to release their cargo during infection, BlaM will cleave the lactam ring, interrupting FRET and causing the cells to fluoresce a different color [155]. Infected and uninfected cells can then be sorted by flow cytometry for further analysis. This technique requires the ability to make chimeric proteins but otherwise does not require specialized equipment. BlaM activity assays have been combined with single virion imaging to indicate that HIV releases cargo by fusion inside endosomes and not fusion at the plasma membrane surface [156].

Bulk fusion provides information on the kinetics of the fusion of the overall population in the solution, including the lag time between when the viruses are exposed to a fusion trigger and when dequenching begins, with a resolution of less than a second [157]. Varying the composition of the liposomes can reveal how lipids impact viral fusion [158]. However, liposomes containing the viral receptor may be hard to prepare if the receptor is a transmembrane protein. These assays cannot resolve intermediate steps like hemifusion, or resolve fusion of individual virions, but can be used to determine conditions interesting for further investigation with single virion tracking with SLBs [137].

It is worth noting that single virion fusion tracking experiments agree with data obtained from bulk fusion experiments. In a study directly comparing the two methods a combination of bulk fusion and single virion tracking showed that cholesterol enhances the extent of Sindbis virus fusion, but increases the lag between binding and fusion at $\mathrm{pH}$ less than 5 , revealing a complicated relationship between lipids and viral fusion proteins in binding and fusion [34]. 


\subsection{Conclusion}

Methods for studying viral entry vary widely in functional characterization, and structural and temporal resolution. No single technique is sufficient to determine all the steps or details of viral entry. Single virion tracking techniques can bridge the gap between detailed structural information and overall infection measurements to inform our understanding of the structure-function relationship of viral fusion proteins. The development of single virion tracking techniques has been dependent on advances in viral labeling, microscopy, and image analysis. These single virion techniques can be applied to study the progression of infection in live cells as well as used in a tightly-controlled biomimetic platform. Top-down cell culture approaches where inhibition or knockout of cellular components reveals their role in viral entry complement bottom-up biomimetic methods where components of interest are methodically added to the experimental platform. Combining information from these different techniques illuminates the framework of steps involved in viral entry and clarifies the mechanisms underlying each step.

\section{References}

1. Marsh M, Helenius A (2006) Virus entry: open sesame. Cell 124:729-740

2. Flint SJ, Enquist LW, Racaniello VR, Skalka AM (2009) Principles of virology, volume I: molecular biology, 3rd edn. ASM Press, Washington DC

3. Suomalainen M, Greber UF (2013) Uncoating of non-enveloped viruses. Curr Opin Virol 3:27-33. https://doi.org/10.1016/j.coviro.2012.12.004

4. White JM, Whittaker GR (2016) Fusion of enveloped viruses in endosomes. Traffic 17:593-614

5. White JM, Delos SE, Brecher M, Schornberg K (2008) Structures and mechanisms of viral membrane fusion proteins: multiple variations on a common theme. Crit Rev Biochem Mol Biol 43:189-219. https://doi.org/10.1080/10409230802058320

6. Matsuyama S, Ujike M, Morikawa S et al (2005) Protease-mediated enhancement of severe acute respiratory syndrome coronavirus infection. Proc Natl Acad Sci USA 102:12543-12547. https://doi.org/10.1073/pnas.0503203102

7. Yamauchi Y, Greber UF (2016) Principles of virus uncoating: cues and the snooker ball. Traffic 17:569-592. https://doi.org/10.1111/tra.12387

8. Harrison SC (2015) Viral membrane fusion. Virology 479-480:498-507. https://doi.org/10. 1016/J.VIROL.2015.03.043

9. Ma Y, He Z, Tan T et al (2016) Real-time imaging of single HIV-1 disassembly with multicolor viral particles. ACS Nano 10:6273-6282. https://doi.org/10.1021/acsnano.6b02462

10. Lakadamyali M, Rust MJ, Babcock HP, Zhuang X (2003) Visualizing infection of individual influenza viruses. Proc Natl Acad Sci USA 100:9280-9285. https://doi.org/10.1073/pnas. 0832269100

11. Spence JS, Krause TB, Mittler E et al (2016) Direct visualization of Ebola virus fusion triggering in the endocytic pathway. MBio 7:e01857-e01815. https://doi.org/10.1128/mBio. 01857-15

12. Costello DA, Lee DW, Drewes J et al (2012) Influenza virus-membrane fusion triggered by proton uncaging for single particle studies of fusion kinetics. Anal Chem 84:8480-8489. https://doi.org/10.1021/ac3006473 
13. Costello DA, Millet JK, Hsia CY et al (2013b) Single particle assay of coronavirus membrane fusion with proteinaceous receptor-embedded supported bilayers. Biomaterials 34:7895-7904. https://doi.org/10.1016/j.biomaterials.2013.06.034

14. Ewers H, Schelhaas M (2012) Analysis of virus entry and cellular membrane dynamics by single particle tracking. Methods Enzymol 506:63-80. https://doi.org/10.1016/B978-0-12391856-7.00028-7

15. Floyd DL, Harrison SC, Van Oijen AM (2010) Analysis of kinetic intermediates in singleparticle dwell-time distributions. Biophys J 99:360-366. https://doi.org/10.1016/j.bpj.2010. 04.049

16. Helenius A, Kartenbeck J, Simons K, Fries E (1980) On the entry of Semliki forest virus into BHK-21 cells. J Cell Biol 84:404-420. https://doi.org/10.1083/JCB.84.2.404

17. Seisenberger G, Ried MU, Endress T et al (2001) Real-time single-molecule imaging of the infection pathway of an adeno-associated virus. Science 294:1929-1932. https://doi.org/10. $1126 /$ science. 1064103

18. Suomalainen M, Nakano MY, Keller S et al (1999) Microtubule-dependent plus- and minus end-directed motilities are competing processes for nuclear targeting of adenovirus. J Cell Biol 144:657-672. https://doi.org/10.1083/JCB.144.4.657

19. Michalet X, Siegmund OHW, Vallerga JV et al (2007) Detectors for single-molecule fluorescence imaging and spectroscopy. J Mod Opt 54:239. https://doi.org/10.1080/09500340600769067

20. Otterstrom J, Van Oijen AM (2013) Visualization of membrane fusion, one particle at a time. Biochemistry 52:1654-1668. https://doi.org/10.1021/bi301573w

21. Shen H, Tauzin LJ, Baiyasi R et al (2017) Single particle tracking: from theory to biophysical applications. Chem Rev 117:7331-7376

22. Brandenburg B, Zhuang X (2007) Virus trafficking-learning from single-virus tracking. Nat Rev Microbiol 5:197-208. https://doi.org/10.1038/nrmicro1615

23. Wang I-H, Burckhardt C, Yakimovich A, Greber U (2018) Imaging, tracking and computational analyses of virus entry and egress with the cytoskeleton. Viruses 10:166. https://doi.org/ $10.3390 / \mathrm{v} 10040166$

24. Axelrod D (2003) Total internal reflection fluorescence microscopy in cell biology. Methods Enzymol 361:1-33. https://doi.org/10.1016/S0076-6879(03)61003-7

25. Mattheyses AL, Simon SM, Rappoport JZ (2010) Imaging with total internal reflection fluorescence microscopy for the cell biologist. J Cell Sci 123:3621-3628. https://doi.org/10. $1242 /$ jcs. 056218

26. Icha J, Weber M, Waters JC, Norden C (2017) Phototoxicity in live fluorescence microscopy, and how to avoid it. BioEssays 39:1700003. https://doi.org/10.1002/bies.201700003

27. Huang L-L, Xie H-Y (2014) Progress on the labeling and single-particle tracking technologies of viruses. Analyst 139:3336-3346. https://doi.org/10.1039/C4AN00038B

28. Liu S-L, Wang Z-G, Zhang Z-L, Pang D-W (2016) Tracking single viruses infecting their host cells using quantum dots. Chem Soc Rev 45:1211-1224. https://doi.org/10.1039/C5CS00657K

29. Sun E, He J, Zhuang X (2013) Live cell imaging of viral entry. Curr Opin Virol 3:34-43. https://doi.org/10.1016/j.coviro.2013.01.005

30. McDonald D, Vodicka MA, Lucero G et al (2002) Visualization of the intracellular behavior of HIV in living cells. J Cell Biol 159:441-452. https://doi.org/10.1083/jcb.200203150

31. Charpilienne A, Nejmeddine M, Berois M et al (2001) Individual rotavirus-like particles containing 120 molecules of fluorescent protein are visible in living cells. J Biol Chem 276:29361-29367. https://doi.org/10.1074/jbc.M101935200

32. Desai P, Person $S$ (1998) Incorporation of the green fluorescent protein into the herpes simplex virus type 1 capsid. J Virol 72:7563-7568

33. Floyd DL, Ragains JR, Skehel JJ et al (2008) Single-particle kinetics of influenza virus membrane fusion. Proc Natl Acad Sci USA 105:15382-15387. https://doi.org/10.1073/pnas. 0807771105 
34. Wessels L, Elting MW, Scimeca D, Weninger K (2007) Rapid membrane fusion of individual virus particles with supported lipid bilayers. Biophys J 93:526-538. https://doi.org/10.1529/ biophysj.106.097485

35. Padilla-Parra S, Matos PM, Kondo N et al (2012b) Quantitative imaging of endosome acidification and single retrovirus fusion with distinct pools of early endosomes. Proc Natl Acad Sci USA 109:17627-17632. https://doi.org/10.1073/pnas.1211714109

36. Kukura P, Ewers H, Müller C et al (2009) High-speed nanoscopic tracking of the position and orientation of a single virus. Nat Methods 6:923-927. https://doi.org/10.1038/nmeth.1395

37. Lee DW, Hsu H-L, Bacon KB, Daniel S (2016b) Image restoration and analysis of influenza virions binding to membrane receptors reveal adhesion-strengthening kinetics. PLoS One 11: e0163437. https://doi.org/10.1371/journal.pone.0163437

38. Carter BC, Shubeita GT, Gross SP (2005) Tracking single particles: a user-friendly quantitative evaluation. Phys Biol 2:60-72. https://doi.org/10.1088/1478-3967/2/1/008

39. Meijering E, Dzyubachyk O, Smal I, van Cappellen WA (2009) Tracking in cell and developmental biology. Semin Cell Dev Biol 20:894-902

40. Sbalzarini IF, Koumoutsakos P (2005) Feature point tracking and trajectory analysis for video imaging in cell biology. J Struct Biol 151:182-195. https://doi.org/10.1016/j.jsb.2005.06.002

41. Ruthardt N, Lamb DC, Bräuchle C (2011) Single-particle tracking as a quantitative microscopy-based approach to unravel cell entry mechanisms of viruses and pharmaceutical nanoparticles. Mol Ther 19:1199-1211. https://doi.org/10.1038/mt.2011.102

42. Georgiou GN, Morrison IEG, Cherry RJ (1989) Digital fluorescence imaging of fusion of influenza virus with erythrocytes. FEBS Lett 250:487-492. https://doi.org/10.1016/0014-5793 (89)80782-3

43. Lowy RJ, Sarkar DP, Chen Y, Blumenthal R (1990) Observation of single influenza virus-cell fusion and measurement by fluorescence video microscopy. Proc Natl Acad Sci USA 87:1850-1854

44. Niles WD, Cohen FS (1991a) Fusion of influenza virions with a planar lipid membrane detected by video fluorescence microscopy. J Gen Physiol 97:1101-1119. https://doi.org/10. 1085/JGP.97.6.1101

45. Niles WD, Cohen FS (1991b) The role of N-acetylneuraminic (sialic) acid in the $\mathrm{pH}$ dependence of influenza virion fusion with planar phospholipid membranes. J Gen Physiol 97:1121-1140. https://doi.org/10.1085/JGP.97.6.1121

46. Sackmann E (1996) Supported membranes: scientific and practical applications. Science 271:43-48. https://doi.org/10.1126/SCIENCE.271.5245.43

47. Tanaka M, Sackmann E (2005) Polymer-supported membranes as models of the cell surface. Nature 437:656-663. https://doi.org/10.1038/nature04164

48. Castellana ET, Cremer PS (2006) Solid supported lipid bilayers: from biophysical studies to sensor design. Surf Sci Rep 61:429-444. https://doi.org/10.1016/J.SURFREP.2006.06.001

49. Bally M, Rydell GE, Zahn R et al (2012) Norovirus GII.4 virus-like particles recognize galactosylceramides in domains of planar supported lipid bilayers. Angew Chemie Int Ed 51:12020-12024. https://doi.org/10.1002/anie.201205972

50. van der Borg G, Braddock S, Blijleven JS et al (2018) Single-particle fusion of influenza viruses reveals complex interactions with target membranes. J Phys Condens Matter 30:204005. https://doi.org/10.1088/1361-648X/aabc21

51. Pace H, Simonsson Nyström L, Gunnarsson A et al (2015) Preserved transmembrane protein mobility in polymer-supported lipid bilayers derived from cell membranes. Anal Chem 87:9194-9203. https://doi.org/10.1021/acs.analchem.5b01449

52. Richards MJ, Hsia C-Y, Singh RR et al (2016) Membrane protein mobility and orientation preserved in supported bilayers created directly from cell plasma membrane blebs. Langmuir 32:2963-2974. https://doi.org/10.1021/acs.langmuir.5b03415

53. Costello DA, Daniel S (2015) Single particle tracking assay to study coronavirus membrane fusion. Methods Mol Biol 1282:183-194. https://doi.org/10.1007/978-1-4939-2438-7_16 
54. Liu H-Y, Chen W-L, Ober CK, Daniel S (2017) Biologically complex planar cell plasma membranes supported on polyelectrolyte cushions enhance transmembrane protein mobility and retain native orientation. Langmuir. https://doi.org/10.1021/acs.langmuir.7b02945

55. Bayerl TM, Bloom M (1990) Physical properties of single phospholipid bilayers adsorbed to micro glass beads. A new vesicular model system studied by $2 \mathrm{H}$-nuclear magnetic resonance. Biophys J 58:357-362. https://doi.org/10.1016/S0006-3495(90)82382-1

56. Johnson SJ, Bayerl TM, McDermott DC et al (1991) Structure of an adsorbed dimyristoylphosphatidylcholine bilayer measured with specular reflection of neutrons. Biophys J 59:289-294. https://doi.org/10.1016/S0006-3495(91)82222-6

57. Matos PM, Marin M, Ahn B et al (2013) Anionic lipids are required for vesicular stomatitis virus $\mathrm{G}$ protein-mediated single particle fusion with supported lipid bilayers. J Biol Chem 288:12416-12425. https://doi.org/10.1074/jbc.M113.462028

58. Hsia C-Y, Richards MJ, Daniel S (2015) A review of traditional and emerging methods to characterize lipid-protein interactions in biological membranes. Anal Methods 7:7076-7094. https://doi.org/10.1039/C5AY00599J

59. Costello DA, Hsia CY, Millet JK et al (2013a) Membrane fusion-competent virus-like proteoliposomes and proteinaceous supported bilayers made directly from cell plasma membranes. Langmuir 29:6409-6419. https://doi.org/10.1021/la400861u

60. Hinterdorfer P, Baber G, Tamm LK (1994) Reconstitution of membrane fusion sites. J Biol Chem 269:20360-20368

61. Tatulian SA, Hinterdorfer ' P, Baber G, Tamm LK (1995) Influenza hemagglutinin assumes a tilted conformation during membrane fusion as determined by attenuated total reflection FTIR spectroscopy. EMBO J 14:5514-5523

62. Szklarczyk OM, González-Segredo N, Kukura P et al (2013) Receptor concentration and diffusivity control multivalent binding of Sv40 to membrane bilayers. PLoS Comput Biol 9: e1003310. https://doi.org/10.1371/journal.pcbi.1003310

63. Dale BM, McNerney GP, Thompson DL et al (2011) Cell-to-cell transfer of HIV-1 via virological synapses leads to endosomal virion maturation that activates viral membrane fusion. Cell Host Microbe 10:551-562. https://doi.org/10.1016/J.CHOM.2011.10.015

64. Felts RL, Narayan K, Estes JD et al (2010) 3D visualization of HIV transfer at the virological synapse between dendritic cells and T cells. Proc Natl Acad Sci USA 107:13336-13341. https://doi.org/10.1073/pnas.1003040107

65. Hubner W, McNerney GP, Chen P et al (2009) Quantitative 3D video microscopy of HIV transfer across T cell virological synapses. Science 323:1743-1747. https://doi.org/10.1126/ science. 1167525

66. Cudmore S, Cossart P, Griffiths G, Way M (1995) Actin-based motility of vaccinia virus. Nature 378:636-638. https://doi.org/10.1038/378636a0

67. Granstedt AE, Brunton BW, Enquist LW (2013) Imaging the transport dynamics of single alphaherpesvirus particles in intact peripheral nervous system explants from infected mice. MBio 4:e00358-e00313. https://doi.org/10.1128/mBio.00358-13

68. Yang X, Forier K, Steukers L et al (2012) Immobilization of pseudorabies virus in porcine tracheal respiratory mucus revealed by single particle tracking. PLoS One 7:e51054. https:// doi.org/10.1371/journal.pone.0051054

69. Lehmann MJ, Sherer NM, Marks CB et al (2005) Actin- and myosin-driven movement of viruses along filopodia precedes their entry into cells. J Cell Biol 170:317-325. https://doi.org/ $10.1083 /$ jcb.200503059

70. van der Schaar HM, Rust MJ, Chen C et al (2008) Dissecting the cell entry pathway of dengue virus by single-particle tracking in living cells. PLoS Pathog 4:e1000244. https://doi.org/10. 1371/journal.ppat.1000244

71. Pelkmans L, Püntener D, Helenius A (2002) Local actin polymerization and dynamin recruitment in SV40-induced internalization of caveolae. Science 296:535-539. https://doi.org/10. 1126/science.1069784 
72. Ewers H, Smith AE, Sbalzarini IF et al (2005) Single-particle tracking of murine polyoma virus-like particles on live cells and artificial membranes. Proc Natl Acad Sci 102:15110-15115. https://doi.org/10.1073/pnas.0504407102

73. Mercer J, Helenius A (2008) Vaccinia virus uses macropinocytosis and apoptotic mimicry to enter host cells. Science 320:531-535. https://doi.org/10.1126/science.1155164

74. Xu H, Hao X, Wang S et al (2015) Real-time imaging of rabies virus entry into living vero cells. Sci Rep 5:11753. https://doi.org/10.1038/srep11753

75. Burckhardt CJ, Suomalainen M, Schoenenberger P et al (2011a) Drifting motions of the adenovirus receptor CAR and immobile integrins initiate virus uncoating and membrane lytic protein exposure. Cell Host Microbe 10:105-117. https://doi.org/10.1016/J.CHOM. 2011.07.006

76. Helmuth JA, Burckhardt CJ, Koumoutsakos P et al (2007) A novel supervised trajectory segmentation algorithm identifies distinct types of human adenovirus motion in host cells. J Struct Biol 159:347-358. https://doi.org/10.1016/J.JSB.2007.04.003

77. Coyne CB, Bergelson JM (2006) Virus-induced Abl and Fyn kinase signals permit coxsackievirus entry through epithelial tight junctions. Cell 124:119-131. https://doi.org/10. 1016/j.cell.2005.10.035

78. Rust MJ, Lakadamyali M, Zhang F, Zhuang X (2004) Assembly of endocytic machinery around individual influenza viruses during viral entry. Nat Struct Mol Biol 11:567-573. https://doi.org/10.1038/nsmb769

79. Peerboom N, Block S, Altgärde N et al (2017) Binding kinetics and lateral mobility of HSV-1 on end-grafted sulfated glycosaminoglycans. Biophys J 113:1223-1234. https://doi.org/10. 1016/J.BPJ.2017.06.028

80. Kunze A, Bally M, Höök F, Larson G (2013) Equilibrium-fluctuation-analysis of single liposome binding events reveals how cholesterol and $\mathrm{Ca} 2+$ modulate glycosphingolipid trans-interactions. Sci Rep 3:1452. https://doi.org/10.1038/srep01452

81. Bally M, Gunnarsson A, Svensson L et al (2011) Interaction of single viruslike particles with vesicles containing glycosphingolipids. Phys Rev Lett 107:188103. https://doi.org/10.1103/ PhysRevLett.107.188103

82. Bally M, Graule M, Parra F et al (2013) A virus biosensor with single virus-particle sensitivity based on fluorescent vesicle labels and equilibrium fluctuation analysis. Biointerphases 8:4. https://doi.org/10.1186/1559-4106-8-4

83. Nasir W, Bally M, Zhdanov VP et al (2015) Interaction of virus-like particles with vesicles containing glycolipids: kinetics of detachment. J Phys Chem B 119:11466-11472. https://doi. org/10.1021/acs.jpcb.5b04160

84. Block S, Zhdanov VP, Höök F (2016) Quantification of multivalent interactions by tracking single biological nanoparticle mobility on a lipid membrane. Nano Lett 16:4382-4390. https:// doi.org/10.1021/acs.nanolett.6b01511

85. Lee D, Allison A, Bacon K et al (2016a) Single-particle tracking shows that a point mutation in the carnivore parvovirus capsid switches binding between host-specific transferrin receptors. J Virol 90:4849-4853. https://doi.org/10.1128/JVI.03204-15

86. Yang S-T, Kiessling V, Simmons JA et al (2015) HIV gp41-mediated membrane fusion occurs at edges of cholesterol-rich lipid domains. Nat Chem Biol 11:424-431. https://doi.org/ 10.1038/nchembio. 1800

87. Yang S-T, Kreutzberger AJB, Kiessling V et al (2017) HIV virions sense plasma membrane heterogeneity for cell entry. Sci Adv 3:e1700338. https://doi.org/10.1126/sciadv.1700338

88. Conboy JC, McReynolds KD, Gervay-Hague J, Saavedra SS (2000) Gp120 binds cooperatively to several biologically relevant glycosphingolipids: quantitative measurements at equilibrium by total internal reflection fluorescence microscopy. Angew Chemie 39:2882-2884 https://doi.org/10.1002/1521-3773(20000818)39:16<2882::AID-ANIE2882>3.0.CO;2-M

89. Conboy JC, McReynolds KD, Gervay-Hague J, Saavedra SS (2002) Quantitative measurements of recombinant HIV surface glycoprotein 120 binding to several glycosphingolipids expressed in planar supported lipid bilayers. J Am Chem Soc 124:968-977. https://doi.org/10. $1021 / \mathrm{ja} 011225 \mathrm{~s}$ 
90. Myszka DG, Sweet RW, Hensley P et al (2000) Energetics of the HIV gp120-CD4 binding reaction. Proc Natl Acad Sci USA 97:9026-9031. https://doi.org/10.1073/PNAS.97.16.9026

91. Kielian MC, Helenius A (1984) Role of cholesterol in fusion of Semliki forest virus with membranes. J Virol 52:281-283

92. Wahlberg JM, Bron R, Wilschut J, Garoff H (1992) Membrane fusion of Semliki forest virus involves homotrimers of the fusion protein. J Virol 66:7309-7318

93. Stevens J, Blixt O, Tumpey TM et al (2006) Structure and receptor specificity of the hemagglutinin from an H5N1 influenza virus. Science 312:404-410. https://doi.org/10.1126/ science. 1124513

94. Hidari KIPJ, Shimada S, Suzuki Y, Suzuki T (2007) Binding kinetics of influenza viruses to sialic acid-containing carbohydrates. Glycoconj J 24:583-590. https://doi.org/10.1007/ s10719-007-9055-y

95. Rydell GE, Dahlin AB, Hook F, Larson G (2009) QCM-D studies of human norovirus VLPs binding to glycosphingolipids in supported lipid bilayers reveal strain-specific characteristics. Glycobiology 19:1176-1184. https://doi.org/10.1093/glycob/cwp103

96. Banerjee S, Maurya S, Roy R (2018) Single-molecule fluorescence imaging: generating insights into molecular interactions in virology. J Biosci:1-22. https://doi.org/10.1007/ s12038-018-9769-y

97. Ehrlich M, Boll W, Van Oijen A et al (2004) Endocytosis by random initiation and stabilization of clathrin-coated pits. Cell 118:591-605. https://doi.org/10.1016/j.cell.2004.08.017

98. Pietiäinen V, Marjomäki V, Upla P et al (2004) Echovirus 1 endocytosis into caveosomes requires lipid rafts, dynamin II, and signaling events. Mol Biol Cell 15:4911-4925. https://doi. org/10.1091/mbc.E04-01-0070

99. Weir DL, Laing ED, Smith IL et al (2014) Host cell virus entry mediated by Australian bat lyssavirus $\mathrm{G}$ envelope glycoprotein occurs through a clathrin-mediated endocytic pathway that requires actin and Rab5. Virol J 11:40. https://doi.org/10.1186/1743-422X-11-40

100. Li Q, Li W, Yin W et al (2017) Single-particle tracking of human immunodeficiency virus type 1 productive entry into human primary macrophages. ACS Nano 11:3890-3903. https://doi. org/10.1021/acsnano.7b00275

101. Liu H, Liu Y, Liu S et al (2011) Clathrin-mediated endocytosis in living host cells visualized through quantum dot labeling of infectious hematopoietic necrosis virus. J Virol 85:6252-6262. https://doi.org/10.1128/JVI.00109-11

102. Liebl D, Difato F, Horníková L et al (2006) Mouse polyomavirus enters early endosomes, requires their acidic $\mathrm{pH}$ for productive infection, and meets transferrin cargo in Rab11-positive endosomes. J Virol 80:4610-4622. https://doi.org/10.1128/JVI.80.9.4610-4622.2006

103. Burckhardt CJ, Suomalainen M, Schoenenberger P et al (2011b) Drifting motions of the adenovirus receptor CAR and immobile integrins initiate virus uncoating and membrane lytic protein exposure. Cell Host Microbe 10:105-117. https://doi.org/10.1016/J.CHOM.2011.07. 006

104. Luisoni S, Suomalainen M, Boucke K et al (2015) Co-option of membrane wounding enables virus penetration into cells. Cell Host Microbe 18:75-85. https://doi.org/10.1016/j.chom.2015. 06.006

105. Meier O, Boucke K, Hammer SV et al (2002) Adenovirus triggers macropinocytosis and endosomal leakage together with its clathrin-mediated uptake. J Cell Biol 158:1119-1131. https://doi.org/10.1083/jcb.200112067

106. Nakano MY, Boucke K, Suomalainen M et al (2000) The first step of adenovirus type 2 disassembly occurs at the cell surface, independently of endocytosis and escape to the cytosol. J Virol 74:7085-7095

107. Damm E-M, Pelkmans L, Kartenbeck J et al (2005) Clathrin- and caveolin-1-independent endocytosis. J Cell Biol 168:477-488. https://doi.org/10.1083/jcb.200407113

108. Lakadamyali M, Rust MJ, Zhuang X (2006) Ligands for clathrin-mediated endocytosis are differentially sorted into distinct populations of early endosomes. Cell 124:997-1009. https:// doi.org/10.1016/j.cell.2005.12.038 
109. Elphick GF, Querbes W, Jordan JA et al (2004) The human polyomavirus, JCV, uses serotonin receptors to infect cells. Science 306:1380-1383. https://doi.org/10.1126/science.1103492

110. Iyengar S, Hildreth JE, Schwartz DH (1998) Actin-dependent receptor colocalization required for human immunodeficiency virus entry into host cells. J Virol 72:5251-5255

111. Sieczkarski SB, Brown HA, Whittaker GR (2003) Role of protein kinase C betaII in influenza virus entry via late endosomes. J Virol 77:460-469. https://doi.org/10.1128/JVI.77.1.460-469. 2003

112. Nicola AV, Straus SE (2004) Cellular and viral requirements for rapid endocytic entry of herpes simplex virus. J Virol 78:7508-7517. https://doi.org/10.1128/JVI.78.14.7508-7517. 2004

113. Vonderheit A, Helenius A (2005) Rab7 associates with early endosomes to mediate sorting and transport of semliki forest virus to late endosomes. PLoS Biol 3:e233. https://doi.org/10. 1371/journal.pbio.0030233

114. Georgi A, Mottola-Hartshornt C, Warner A et al (1990) Detection of individual fluorescently labeled reovirions in living cells. Microbiology 87:6579-6583

115. Xiao P-J, Samulski RJ (2012) Cytoplasmic trafficking, endosomal escape, and perinuclear accumulation of adeno-associated virus type 2 particles are facilitated by microtubule network. J Virol 86:10462-10473. https://doi.org/10.1128/JVI.00935-12

116. Arhel N, Genovesio A, Kim K-A et al (2006) Quantitative four-dimensional tracking of cytoplasmic and nuclear HIV-1 complexes. Nat Methods 3:817-824. https://doi.org/10. 1038/nmeth928

117. Vaughan JC, Brandenburg B, Hogle JM, Zhuang X (2009) Rapid actin-dependent viral motility in live cells. Biophys J 97:1647-1656. https://doi.org/10.1016/j.bpj.2009.07.011

118. Bremner KH, Scherer J, Yi J et al (2009) Adenovirus transport via direct interaction of cytoplasmic dynein with the viral capsid hexon subunit. Cell Host Microbe 6:523-535. https://doi.org/10.1016/J.CHOM.2009.11.006

119. Wang I-H, Burckhardt CJ, Yakimovich A et al (2017) The nuclear export factor CRM1 controls juxta-nuclear microtubule-dependent virus transport. J Cell Sci 130:2185-2195. https://doi.org/10.1242/jcs.203794

120. Jun S, Ke D, Debiec K et al (2011) Direct visualization of HIV-1 with correlative live-cell microscopy and cryo-electron tomography. Structure 19:1573-1581. https://doi.org/10.1016/ J.STR.2011.09.006

121. Chen J, Grunwald D, Sardo L et al (2014) Cytoplasmic HIV-1 RNA is mainly transported by diffusion in the presence or absence of gag protein. Proc Natl Acad Sci USA 111:E5205-E5213. https://doi.org/10.1073/pnas.1413169111

122. Albanese A, Arosio D, Terreni M, Cereseto A (2008) HIV-1 pre-integration complexes selectively target decondensed chromatin in the nuclear periphery. PLoS One 3:e2413. https://doi.org/10.1371/journal.pone.0002413

123. Babcock HP, Chen C, Zhuang X (2004) Using single-particle tracking to study nuclear trafficking of viral genes. Biophys J 87:2749-2758. https://doi.org/10.1529/biophysj.104. 042234

124. Antinone SE, Shubeita GT, Coller KE et al (2006) The Herpesvirus capsid surface protein, VP26, and the majority of the tegument proteins are dispensable for capsid transport toward the nucleus. J Virol 80:5494-5498. https://doi.org/10.1128/JVI.00026-06

125. Luxton GWG, Haverlock S, Coller KE et al (2005) Targeting of herpesvirus capsid transport in axons is coupled to association with specific sets of tegument proteins. Proc Natl Acad Sci USA 102:5832-5837. https://doi.org/10.1073/pnas.0500803102

126. Wolfstein A, Nagel C-H, Radtke K et al (2006) The inner tegument promotes herpes simplex virus capsid motility along microtubules in vitro. Traffic 7:227-237. https://doi.org/10.1111/j. 1600-0854.2005.00379.x

127. Döhner K, Radtke K, Schmidt S, Sodeik B (2006) Eclipse phase of herpes simplex virus type 1 infection: efficient dynein-mediated capsid transport without the small capsid protein VP26. J Virol 80:8211-8224. https://doi.org/10.1128/JVI.02528-05 
128. Strunze S, Trotman LC, Boucke K, Greber UF (2005) Nuclear targeting of adenovirus type 2 requires CRM1-mediated nuclear export. Mol Biol Cell 16:2999-3009. https://doi.org/10. 1091/mbc.E05-02-0121

129. Miyauchi K, Kim Y, Latinovic O et al (2009) HIV enters cells via endocytosis and dynamindependent fusion with endosomes. Cell 137:433-444. https://doi.org/10.1016/j.cell.2009.02. 046

130. Markosyan RM, Cohen FS, Melikyan GB (2005) Time-resolved imaging of HIV-1 Env-mediated lipid and content mixing between a single virion and cell membrane. Mol Biol Cell 16:5502-5513. https://doi.org/10.1091/mbc.e05-06-0496

131. Melikyan GB, Barnard RJO, Abrahamyan LG et al (2005) Imaging individual retroviral fusion events: from hemifusion to pore formation and growth. Proc Natl Acad Sci USA 102:8728-8733. https://doi.org/10.1073/pnas.0501864102

132. Jha NK, Latinovic O, Martin E et al (2011) Imaging single retrovirus entry through alternative receptor isoforms and intermediates of virus-endosome fusion. PLoS Pathog 7:e1001260. https://doi.org/10.1371/journal.ppat.1001260

133. Padilla-Parra S, Marin M, Kondo N, Melikyan GB (2012a) Synchronized retrovirus fusion in cells expressing alternative receptor isoforms releases the viral core into distinct sub-cellular compartments. PLoS Pathog 8:e1002694. https://doi.org/10.1371/journal.ppat.1002694

134. Le Blanc I, Luyet P-P, Pons V et al (2005) Endosome-to-cytosol transport of viral nucleocapsids. Nat Cell Biol 7:653-664. https://doi.org/10.1038/ncb1269

135. Blijleven JS, Boonstra S, Onck PR et al (2016) Mechanisms of influenza viral membrane fusion. Semin Cell Dev Biol 60:78-88

136. Zhang Y, Dudko OK (2015) Statistical mechanics of viral entry. Phys Rev Lett 114:018104. https://doi.org/10.1103/PhysRevLett.114.018104

137. Van Duijl-Richter MKS, Blijleven JS, van Oijen AM, Smit JM (2015) Chikungunya virus fusion properties elucidated by single-particle and bulk approaches. J Gen Virol 96:2122-2132. https:// doi.org/10.1099/vir.0.000144

138. Chao LH, Klein DE, Schmidt AG et al (2014) Sequential conformational rearrangements in flavivirus membrane fusion. elife 3:e04389. https://doi.org/10.7554/eLife.04389

139. Kim IS, Jenni S, Stanifer ML et al (2017) Mechanism of membrane fusion induced by vesicular stomatitis virus G protein. Proc Natl Acad Sci USA 114:E28-E36. https://doi.org/ 10.1073/pnas. 1618883114

140. Costello DA, Whittaker GR, Daniel S (2015) Variations in pH sensitivity, acid stability, and fusogenicity of three influenza virus H3 subtypes. J Virol 89:350-360. https://doi.org/10.1128/ JVI.01927-14

141. Ivanovic T, Choi JL, Whelan SP et al (2013) Influenza-virus membrane fusion by cooperative fold-back of stochastically induced hemagglutinin intermediates. elife 2013:e00333. https:// doi.org/10.7554/eLife.00333

142. Ivanovic T, Harrison SC (2015) Distinct functional determinants of influenza hemagglutininmediated membrane fusion. elife 4:e11009. https://doi.org/10.7554/eLife.11009

143. Lee DW, Thapar V, Clancy P, Daniel S (2014) Stochastic fusion simulations and experiments suggest passive and active roles of hemagglutinin during membrane fusion. Biophys J 106:843-854. https://doi.org/10.1016/j.bpj.2013.12.048

144. Hsu H-L, Millet JK, Costello DA et al (2016) Viral fusion efficacy of specific H3N2 influenza virus reassortant combinations at single-particle level. Sci Rep 6:35537. https://doi.org/10. 1038/srep35537

145. Otterstrom JJ, Brandenburg B, Koldijk MH et al (2014) Relating influenza virus membrane fusion kinetics to stoichiometry of neutralizing antibodies at the single-particle level. Proc Natl Acad Sci USA 111:E5143-E5148. https://doi.org/10.1073/pnas.1411755111

146. White J, Matlin K, Helenius A (1981) Cell fusion by Semliki forest, influenza, and vesicular stomatitis viruses. J Cell Biol 89:674-679. https://doi.org/10.1083/JCB.89.3.674 
147. Markosyan RM, Bates P, Cohen FS, Melikyan GB (2004) A study of low pH-induced refolding of Env of avian sarcoma and leukosis virus into a six-helix bundle. Biophys J 87:3291-3298. https://doi.org/10.1529/biophysj.104.047696

148. Melikyan GB, Barnard RJO, Markosyan RM et al (2004) Low pH is required for avian sarcoma and leukosis virus Env-induced hemifusion and fusion pore formation but not for pore growth. J Virol 78:3753-3762. https://doi.org/10.1128/JVI.78.7.3753-3762.2004

149. Blumenthal R, Sarkar DP, Durell S et al (1996) Dilation of the influenza hemagglutinin fusion pore revealed by the kinetics of individual cell-cell fusion events. J Cell Biol 135:63-71. https://doi.org/10.1083/JCB.135.1.63

150. Spruce AE, Iwata A, White JM, Almers W (1989) Patch clamp studies of single cell-fusion events mediated by a viral fusion protein. Nature 342:555-558. https://doi.org/10.1038/ $342555 \mathrm{a} 0$

151. Spruce AE, Iwata A, Almers W (1991) The first milliseconds of the pore formed by a fusogenic viral envelope protein during membrane fusion. Proc Natl Acad Sci USA 88:3623-3627. https://doi.org/10.1073/pnas.88.9.3623

152. Cohen FS, Melikyan GB (1998) Methodologies in the study of cell-cell fusion. Methods 16:215-226. https://doi.org/10.1006/meth.1998.0670

153. Struck DK, Hoekstra D, Pagano RE (1981) Use of resonance energy transfer to monitor membrane fusion. Biochemistry 20:4093-4099. https://doi.org/10.1021/bi00517a023

154. Hoekstra D, De Boer T, Klappe K, Wilschut J (1984) Fluorescence method for measuring the kinetics of fusion between biological membranes. Biochemistry 23:5675-5681. https://doi. org/10.1021/bi00319a002

155. Cavrois M, de Noronha C, Greene WC (2002) A sensitive and specific enzyme-based assay detecting HIV-1 virion fusion in primary T lymphocytes. Nat Biotechnol 20:1151-1154. https://doi.org/10.1038/nbt745

156. de la Vega M, Marin M, Kondo N et al (2011) Inhibition of HIV-1 endocytosis allows lipid mixing at the plasma membrane, but not complete fusion. Retrovirology 8:99. https://doi.org/ $10.1186 / 1742-4690-8-99$

157. Clague MJ, Schoch C, Blumenthal R (1991) Delay time for influenza virus hemagglutinininduced membrane fusion depends on hemagglutinin surface density. J Virol 65:2402-2407

158. Nieva JL, Bron R, Corver J, Wilschut J (1994) Membrane fusion of Semliki Forest virus requires sphingolipids in the target membrane. EMBO J 13:2797-2804 